\title{
Vegetation phenology in Greenland and links to cryospheric change
}

\author{
Jeffery A. THOMPSON, ${ }^{1,2}$ Lora S. KOENIG ${ }^{2}$ \\ ${ }^{1}$ Minnesota Supercomputing Institute, 599 Walter Library, 117 Pleasant St S.E., Minneapolis, MN 55455, USA. \\ Email: jathomps@umn.edu \\ ${ }^{2}$ National Snow and Ice Data Center (NSIDC), Cooperative Research Institute for Research in Environmental Sciences, \\ University of Colorado Boulder, 448 UCB, Boulder, CO 80309-0449, USA
}

\begin{abstract}
Recent greening of vegetation across the Arctic is associated with warming temperatures, hydrologic change and shorter snow-covered periods. Here we investigated trends for a subset of arctic vegetation on the island of Greenland. Vegetation in Greenland is unique due to its close proximity to the Greenland Ice Sheet and its proportionally large connection to the Greenlandic population through the hunting of grazing animals. The aim of this study was to determine whether or not longer snow-free periods (SFPs) were causing Greenlandic vegetation to dry out and become less productive. If vegetation was drying out, a subsequent aim of the study was to determine how widespread the drying was across Greenland. We utilized a 15-year time-series obtained by the MODerate Resolution Imaging Spectroradiometer (MODIS) to analyze the Greenland vegetation by deriving descriptors corresponding with the SFP, the number of cumulative growing degree-days and the time-integrated Normalized Difference Vegetation Index. While the productivity of most vegetated areas increased in response to longer growing periods, there were localized regions that exhibited signs consistent with the drying hypothesis. In these areas, vegetation productivity decreased in response to longer SFPs and more accumulated growing degree-days.
\end{abstract}

KEYWORDS: Arctic warming, Greenland, land surface phenology, MODIS, seasonality

\section{INTRODUCTION AND BACKGROUND}

In recent years, the rate of climatic warming in the Arctic has been roughly double that of the lower latitudes, an occurrence referred to as Arctic amplification (Serreze and others, 2000; Screen and Simmonds, 2010). Although they operate on different spatial and temporal scales, there are a number of causes of this amplification. They include changes in: sea ice extent and concentration, which influence the exchange of vertical heat fluxes between the Arctic Ocean and atmosphere (Screen and Simmonds, 2010); water vapor and cloud cover that cause fluctuations in down-welling longwave radiation (Francis and Hunter, 2006); the convergence of atmospheric and oceanic heat flux (Graversen and others, 2008) among others. Increased photosynthetic capacity of vegetation in response to longer snow-free periods (SFPs) (Déry and Brown, 2007; Sturm and others, 2005) is another phenomenon associated with Arctic amplification (Bhatt and others, 2010; Beck and Goetz, 2011).

This increase in photosynthetic capacity of vegetation has also been accompanied by an expansion of woody shrubs in the tundra (Sturm and others, 2001; Markus and others, 2009). Myers-Smith and others (2011) noted there are several important implications associated with shrub expansion. Firstly, it will alter the exchange of energy, carbon and water fluxes between the atmosphere and biosphere. It will also likely change permafrost distributions and impact active layer dynamics by altering snow regimes and reducing spring surface albedo. Shrub expansion will influence nutrient cycling in the Arctic, as shrubs increase liter inputs into the soil. Continued expansion may eventually disrupt food webs in the Arctic, as it has the potential to reduce lichen abundance. This would negatively impact caribou and reindeer populations. Shrub expansion may also increase fire frequency; Higuera and others (2008) reported that fire was more prevalent in the past when temperatures and moisture were higher, and shrubs were more abundant.

Shrub expansion in the Arctic is a manifestation of increased plant productivity in response to changes in energy fluxes associated with longer SFPs and warming temperatures. This response is consistent with the eco-hydrological framework proposed by Budyko (1974). Budyko (1974) suggested that ecosystems could be classified according to the primary environmental factor that limits vegetation growth in the system. Under the Budyko (1974) framework, ecosystems are characterized as being water or energy limited. Because photosynthesis is a temperature-sensitive process (Nobel, 2009), low temperatures in the Arctic imply that it is energy limited. According to the framework, vegetation productivity should increase when more energy flows in the system and temperatures increase.

The Budyko (1974) framework is useful, but in order for plants to effectively utilize additional energy inputs, they still require regular access to water during the growing period for photosynthesis to occur (Nobel, 2009). There is evidence to suggest that water regimes in the Arctic are changing. Derksen and Brown (2012) used remotely sensed data to estimate weekly snow cover extent across the Northern Hemisphere from 1963 to 2012. Their analysis revealed a statistically significant decline in spring (April-June) snow extent since 2008. Spring corresponds with the time when snow cover is increasingly confined to higher latitudes (Derksen and Brown, 2012). Although the link is indirect, reduced snow cover extent may also be indicative of 
smaller snow-packs, and an associated reduction in the overall water content of the pack. If snow water content is lower, the combination of longer SFPs and smaller packs would reduce soil moisture and thereby diminish plant productivity (Nobel, 2009).

There are indications that vegetation photosynthetic capacity has declined in recent years in the Arctic. Using a time series of Normalized Difference Vegetation Index (NDVI), Bhatt and others (2013) observed that vegetation productivity had declined since 2010. Bhatt and others (2013) also reported that decreased productivity was associated with an increase in growing degree-days (Summer Warmth Index).

An alternative hypothesis is that changes in surface hydology also contributed to the reduction in photosynthetic capacity of Arctic vegetation. Insufficient access to water during longer SFPs would also reduce photosythentic activity, thereby decreasing plant productivity. Several recent remote-sensing studies (e.g. Smith and others, 2005; Watts and others, 2014; Carroll and others, 2016) have also reported that surface hydology is changing across the Arctic. If these changes are reducing the amount of water available to plants during the growing period, it could also account for the decrease in vegetation productivity reported by Bhatt and others (2013).

In Greenland, several studies have reported changes in surface hydrologic conditions and plant available water. Callaghan and others (2011) reported drying ponds and related changes in vegetation at their study site on Disko Island. Similar results were reported by Ellebjerg and others (2008), Daniëls and de Molenaar (2011) and Daniëls and others (2011). In all cases, changes in surface hydrologic conditions had a localized impact on vegetation. In particular, Ellebjerg and others (2008) reported that faster melting snow cover in 1 year resulted in lower soil moisture that reduced plant productivity in the following year.

The results of these Greenland studies are intriguing. They suggest that the impact of climatic warming on plants in the Arctic may be more complex than the Budyko framework predicts, and that has been previously observed by remote sensing (e.g. Jia and others, 2009; Bhatt and others, 2010). Because they were all ground-based studies, with limited spatial coverage and few sampling locations, it is hard to extend the result of previous studies to the whole of Greenland. To date, there have been no investigations into the spatial extent of vegetative drying there. There are some recent indications that the drying phenomenon may be more prolific. In 2017, a fire broke out on the tundra, not far from Sisimiut, Greenland (Kahn, 2017; Voiland, 2017). Though occasionally detected from space by satellites, Greenland is not generally associated with wild fire. It is unclear what role hydrologic change and vegetation desiccation may have played in the 2017 fires.

In this study, we investigated the links between changes in snow seasonality and vegetation phenology in Greenland using remote sensing. Snow cover is a key factor that influences vegetation phenology in the Arctic. When present on the land surface, it affects the aboveground microclimate, subsurface hydrology, soil geochemistry and soil heat fluxes (Pomeroy and Brun, 2001; Walker and others, 2001). The insulating properties of winter snow cover are critically important for plants in the Arctic: it reduces the free exchange of heat between the ground and atmosphere, protecting them during the cold, harsh winter months. The timing of snowmelt also regulates annual phenological cycles and growth; its disappearance initiates photosynthesis and accelerates vegetative growth (Wielgolaski and Inouye, 2013).

Because deeper snow packs take longer to melt, they reduce the length of the growing season. In contrast, shallower packs melt faster, thereby lengthening growing periods (Walker and others, 2001). The timing of melt directly modulates soil moisture and the amount of water available to vegetation (Walker and others, 2001). Longer SFPs, combined with warmer temperatures and longer growing periods, also impact plant reproductive phenology by facilitating seed production and development (Wielgolaski and Inouye, 2013). Lastly, there are also inter-annual feedbacks between vegetation and snow cover. The presence and type of vegetation affects snow accumulation, snow depths and the persistence of snow cover (Pomeroy and others, 2001; Myers-Smith and others, 2011). In turn, the amount of accumulated snow and duration of snow cover influence plant phenology and growth in the following year.

Here, we investigated changes in snow seasonality and its links to vegetation phenology in Greenland. Vegetation phenology can be assessed using either ground-based observations, or from remotely sensed imagery. Although using remote sensing for phenology is referred to as land surface phenology, for readability we simply use the term vegetation phenology here. For this analysis, we employed three remotely sensed datasets obtained by the MODerate Resolution Imaging Spectroradiometer (MODIS) from 2000 to 2014. The $500 \mathrm{~m}$ MODIS daily snow cover product (MOD10A1) was used to estimate the length of the SFP, the $250 \mathrm{~m} 16 \mathrm{~d}$ composite vegetation data (MOD13q1) was used to derive phenological descriptors and estimate vegetation productivity. The $1 \mathrm{~km}$ daily land surface temperature (LST)/emissivity product (MOD11A1) was used to determine the number of growing degree-days during each growing season. The primary aim of this study was to determine whether or not Greenlandic vegetation was drying out as a result of longer SFPs and warmer conditions during the growing period. If there was evidence to support the drying hypothesis, a subsequent aim of the study was to determine how prevalent the phenomenon was.

\section{SITE DESCRIPTION}

\section{Study area}

Approximately $80 \%$ of Greenland is permanently covered by ice (i.e. the Greenland Ice Sheet), leaving only $\sim 20 \%$ of the perimeter inhabitable by humans, animals and vegetation (Fig. 1). Our study area included both the land and icecovered regions of Greenland with specific focus on the terrestrial land and vegetated areas. Although small, Greenland's vegetated areas are of primary importance to its indigenous population. Subsistence hunting is a significant aspect of both their livelihood strategies and their cultural identity (Andersen and Poppel, 2002). It is well documented that the ice-covered regions of Greenland have experienced major changes in the past two decades including more than quadrupling its mass loss (e.g. $-142 \pm$ 49 gigatonnes per year from 1992 to 2011; Shepherd and others, 2012) and increasing surface melt and subsequent runoff (e.g. Enderlin and others, 2014). 


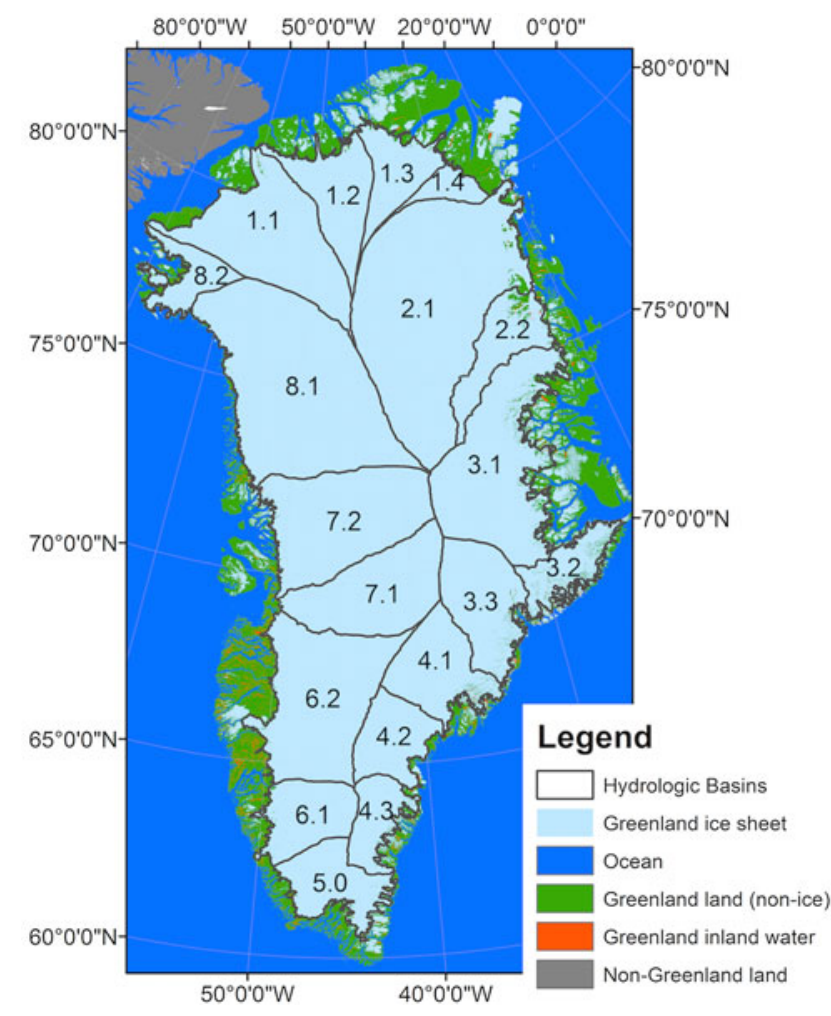

Fig. 1. This study focuses on terrestrial Greenland (green) and associated ice sheet hydrological basins (Zwally and others, 2012) that deliver meltwater to this area. Together the sub-basins make up the larger basins that are referred to in the text (e.g. sub-basins 6.1 and 6.2 make up basin 6.0; 8.1 and 8.2 comprise 8.0, etc.).

\section{DATA AND METHODS}

\section{Remote-sensing data}

For this analysis, three different Level 3 MODIS products were employed. These included the $250 \mathrm{~m}$ MODIS $16 \mathrm{~d}$ composite Vegetation Product (MOD13Q1 - Huete and others, 2002), the daily $500 \mathrm{~m}$ Snow Cover Product (MOD10A1 - Hall and others, 2002) and the daily $1 \mathrm{~km}$ LST/emissivity product (MOD11A1 - Wan, 2008). All data were from Collection 5, and all tiles comprising the land surface of Greenland were used when available (h15v0203; h16v00-02; h17v00-03). For each collection, all available tiles from 2000 to 2014 from Julian days 087-305 were used. These data were freely available and were obtained from NASA's Earthdata website.

\section{Vegetation data}

The $250 \mathrm{~m}$ NDVI subset of MOD13Q1 was used to estimate the productivity of Greenlandic vegetation (Solano and others, 2010). NDVI is a normalized, band ratio algorithm (Tucker, 1979) and was calculated as:

$$
\mathrm{NDVI}=\frac{\rho_{\mathrm{b} 2}-\rho_{\mathrm{b} 1}}{\rho_{\mathrm{b} 2}+\rho_{\mathrm{b} 1}}
$$

where $\rho_{\mathrm{b} 1}$ was MODIS band $1(0.620-0.670 \mu \mathrm{m})$ and $\rho_{\mathrm{b} 2}$ was MODIS band $2(0.841-0.876 \mu \mathrm{m})$ on the MODIS Terra instrument. This product is a $16 \mathrm{~d}$ composite corresponding with the maximum NDVI value with the smallest sensor view angle obtained during the $16 \mathrm{~d}$ observation period.
Sellers (1985) demonstrated that NDVI is a near linear indicator of photosynthetic capacity in vegetation. This fact, in combination with the high temporal sampling frequency of sensors like the Advanced Very High Resolution Radiometer (AVHRR), and the relatively long time series (for satellite data) has meant that NDVI has most widely used vegetation index for remote-sensing phenological studies, particularly in the Arctic (e.g. Jia and others, 2009; Bhatt and others, 2010).

\section{Snow data}

The $500 \mathrm{~m}$ Fractional Snow Cover (FSC) data from the MOD10A Daily Snow Product (Riggs and others, 2006) was used to estimate the length of the SFP for terrestrial Greenland. This product uses the Normalized Difference Snow Index (NDSI; Dozier, 1989) and an empirical regression equation (Salomonson and Appel, 2004) to estimate the fraction of snow covering (FSC) individual pixels in the scene. The NDSI and the FSC were calculated as:

$$
\begin{gathered}
N D S I=\frac{\rho_{b 6}-\rho_{b 4}}{\rho_{b 6}+\rho_{b 4}} \\
F S C=0.06+1.21 \times N D S I
\end{gathered}
$$

where $\rho_{\mathrm{b} 4}$ was band $4(0.545-0.565 \mu \mathrm{m})$ and $\rho_{\mathrm{b} 6}$ was band 6 (1.628-1.652 $\mu \mathrm{m})$ from MODIS Terra.

\section{Temperature data}

The $1 \mathrm{~km}$ daily, daytime LST data from MOD11A1 were also used in this analysis (Wan, 2007). These data estimate LSTs using MODIS infrared bands and a generalized split window algorithm (Wan and Dozier, 1996). The accuracy of these data have been assessed, with Wan (2008) reporting that the remotely sensed LST data were within $1^{\circ} \mathrm{C}$ of actual temperatures in most cases when compared against in situ data. These data have been used to estimate LSTs for agriculture (Coll and others, 2005), lakes (Wan and others, 2002), and ice sheets (Hall and others, 2013). They have also been employed to estimate evapotranspiration in agricultural systems (McCabe and Wolock, 2010).

\section{Spatial data and masks}

Several other ancillary remotely sensed datasets were also used in this analysis. These included: the $250 \mathrm{~m}$ MODIS and SRTM derived land water mask (MOD44W - Carroll and others, 2009); the mosaic of Greenland (MOG - Haran and others, 2013); elevation data from the Greenland Ice Mapping Project (GIMP - Howat and others, 2014); and the Greenland Ice Sheet drainage basin data (Zwally and others, 2012). These data were used to separate land from ice and water and they were also used to subset Greenland into regions of interest for the study.

\section{Land surface descriptors}

\section{Deriving snow seasonality descriptors}

Snow seasonality descriptors were derived using the FSC subset of the MOD10A1 data (Salomonson and Appel, 2004; Riggs and others, 2006). Descriptors for the SFP were derived using the snow cover melt date (SCMD) in the spring and the onset of snow cover (SCOD) in the fall 


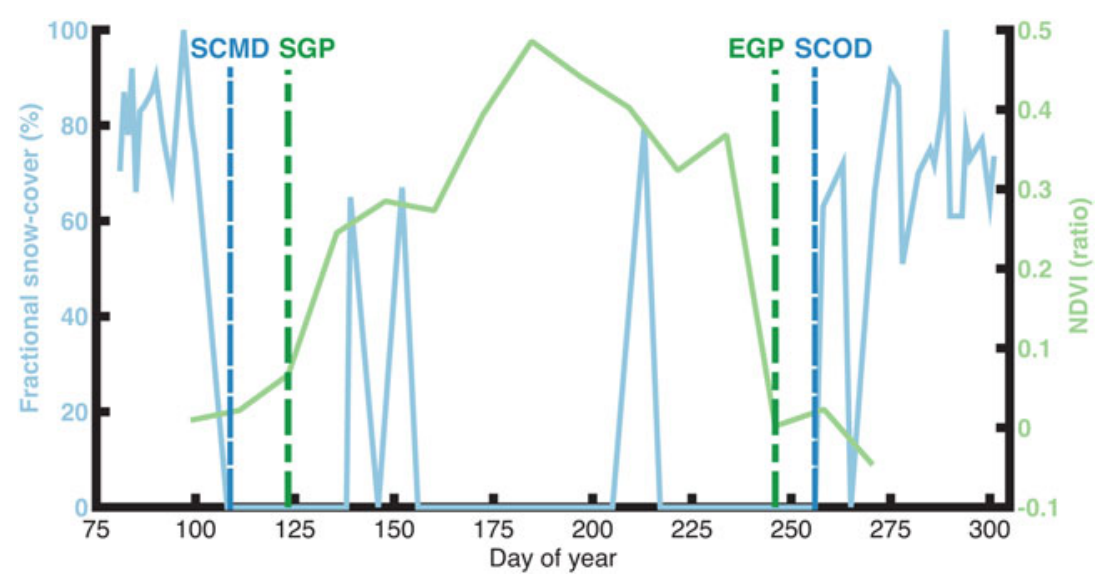

Fig. 2. Schematic representation illustrating the relationship between the snow cover descriptors (vertical blue lines; Snow Cover Melt/Onset Date) estimated using the Fractional Snow Cover data (blue line) and the vegetation phenology descriptors (vertical green lines; Start/End of Growing Period) estimated using the Normalized Difference Vegetation Index data (green line).

(Fig. 2). The duration of the SFP was calculated directly from SCMD and SCOD as:

$$
\mathrm{SFP}=\mathrm{SCMD}-\mathrm{SCOD}
$$

Here the snow seasonality descriptors were defined on a per pixel basis. The descriptor corresponding with seasonal SCMD was identified as the first day that the MOD10A1 FSC product reported snow cover as having disappeared $(\mathrm{FSC}=0 \%$ ). Similarly, the descriptor date corresponding with SCOD was the last date in the year that a pixel was observed to be snow-free ( $\mathrm{FSC}=0 \%$ ).

\section{Deriving vegetation phenology and productivity descriptors}

Vegetation phenology and productivity descriptors were derived from the MOD13q1 NDVI data. Descriptors corresponding with the start of the growing period (SGP), end of the growing period (EGP), duration of the growing period (DGP) and vegetation productivity were also estimated on a per pixel basis. SGP and EGP were estimated using thresholds derived from an averaged NDVI time series of vegetated areas around Greenland. The derivation of the threshold and the averaged time series are described in the Supplementary Materials (Fig. S3). The threshold applied to each was calculated as:

$$
\text { Theshold }_{\mathrm{NDVI}}=\text { Range }_{\mathrm{NDVI}} \times 0.30+\text { Minimum }_{\mathrm{NDVI}},
$$

where the Range $\mathrm{NDV}_{\mathrm{I}}$ was the average range of the average NDVI time series (Fig. S3) and Minimum ${ }_{\text {NDVI }}$ was the average minimum from this time series. These averages were estimated directly from Fig. S3, and the threshold used here was 0.06 . This was $\sim 10 \%$ of the average maximum NDVI values from the vegetated ROI pixels in Figure 1.

It is well known that the presence of on ground snow cover artificially depresses the NDVI signal (Huete and others, 2002), thereby influencing the determination of phenological descriptor dates from remotely sensed imagery (Justice and others, 1986; Myneni and others,
1997). For this reason, additional constraints were used in conjunction with the NDVI threshold to estimate the land surface phenology descriptors. The snow seasonality descriptors were also used to determine when a given pixel was within the SFP. The SGP date was defined as the first date in the SFP that the NDVI value was $\geq 0.06$ and the EGP date was defined as the last date in the SFP that the NDVI value was $\geq 0.06$. Land surface phenology descriptors were only derived for vegetated pixels, as described in the Supplementary Materials.

In addition to the descriptors corresponding with the start and end of the growing period, the productivity of the vegetation was also estimated. Productivity was approximated using the area under the seasonal NDVI curve (time-integrated NDVI; TI-NDVI). The TI-NDVI provided an assessment of a pixel's gross primary productivity, and is an important phenological descriptor of vegetation dynamics (Reed and others, 1994). Yearly comparisons of TI-NDVI values provide an estimate of inter-annual differences in vegetative productivity from year to year. Bhatt and others (2013) used several years of TI-NDVI data from an AVHRR image time series to characterize climate relative changes in vegetation productivity across the pan-Arctic region. Whereas the AVHRR data employed by Bhatt and others (2013) have a relatively coarse spatial resolution $(\sim 5 \times 5$ $\mathrm{km})$, the MOD13q1 data used here have comparatively finer spatial resolution $(250 \times 250 \mathrm{~m})$.

\section{Estimating accumulated growing degree-days}

The numbers of accumulated growing degree-days (AGDD) were estimated for each vegetated pixels using MOD11A1 data. Photosynthesis is a temperature-sensitive biological process (Nobel, 2009) and temperatures $<0^{\circ} \mathrm{C}$ generally suppressed plant growth. Below this temperature, plants have a limited ability to produce catalytic enzymes required for photosynthetic processes (Kirschbaum and Farquhar, 1984), which suppresses tissue formation (Körner, 1998). Here, AGDD were defined as the number of days during the SFP when the LST $>0{ }^{\circ} \mathrm{C}$ were recorded. This descriptor was also defined on a per pixel basis for each year and was derived from the daytime LST observations. 


\section{Sensitivity analysis}

There were two major sources of uncertainty associated with the derived remotely sensed snow seasonality and vegetation phenology descriptors described above. Firstly, melting snow cover influences NDVI time series. In particular, it influences the derivation of both the SGP and EGP descriptors (Reed and others, 2003, 2009; White and others, 2009). A sensitivity analysis was performed to determine what effect the selection of different FSC thresholds had on the derivation of phenological descriptor dates. The details of this analysis are in the Supplementary Materials.

In addition, changes in cloud climatology can confound the results of remote-sensing studies. Snow/cloud misclassification remains a perennial challenge in optical remote sensing (e.g. Hall and Riggs, 2007). Because optical sensors cannot penetrate cloud cover in areas with increasing cloud cover, there is uncertainty regarding the status of the land surface. Here, trends in the number of cloudy days were also assessed (Supplementary Materials). These results were used to inform subsequent investigations, specifically the joint descriptor analysis for individual drainage basins (section 'Basin-wide trend analysis').

\section{Analytical methods}

\section{Greenland-wide trend analysis}

To understand how increased energy inputs associated with Arctic amplification were impacting vegetation, we calculated long-term averages for each of the three individual descriptors (SFP, TI-NDVI and AGDD) using the time series of all vegetated pixels. For each year, we counted both the number of pixels that exceeded $(\geq)$ or fell below $(<)$ the long-term average of each descriptor. The yearly counts were then analyzed to determine whether or not the proportion of pixels in each category remained stable across the study period. The temporal trends in those counts were assessed using generalized linear models from the Statistics Toolbox of MATLAB (MathWorks, 2016).

In addition to the analysis of the individual snow seasonality and vegetation phenology descriptors, we also undertook a similar analysis of joint descriptors. For this, we examined pair-wise combinations of the descriptors (e.g. TI-NDVI and AGDD; AGDD and SFP; SFP and TI-NDVI). For each year, we counted the number of pixels above $(\geq)$ and below $(<)$ the long-term averages of both descriptors. Temporal trends related to the fraction of pixels in each joint class were also assessed using generalized linear models from the Statistics Toolbox of MATLAB (MathWorks, 2016).

\section{Basin-wide trend analysis}

In addition to the analysis of vegetated areas around Greenland, a similar analysis was performed for individual drainage basins in Western Greenland (Fig. 1). Basins in Eastern Greenland were not included in this analysis, as the analysis of cloud cover (Supplementary Materials) revealed there was a substantial increase in the number of cloudy days that occurred during the study. As with the Greenland-wide analysis, the long-term basin averages for each descriptor were used to assess the yearly fraction of pixels in the basin that exceed $(\geq)$ and fell below $(<)$ the long-term average. Trends in the descriptors were assessed for the individual basins using generalized linear models from the Statistics Toolbox of MATLAB (MathWorks, 2016).

\section{Mapped results}

Spatial patterns in the yearly joint comparisons (section 'Deriving vegetation phenology and productivity descriptors') were also analyzed by mapping the results of the joint analysis (section 'Greenland-wide trend analysis'). Results from Hall and others (2013) were used to identify years where temperatures across the Greenland Ice Sheet were: cooler (2000), average (2004) and warmer than usual (2010). Although Hall and others (2013) only examined ice surface temperatures in their study, it was thought the atmospheric conditions influencing ice surface temperatures in those years would likely have also affected LSTs off the ice in a similar manner.

\section{RESULTS}

\section{Greenland-wide trends in snow seasonality, growing degree-days and vegetation descriptors}

The results indicated that most vegetated surfaces experienced an increase in AGDD throughout the study period (Fig 3b). For the joint descriptors, the results indicated an increase in the proportions of pixels that experienced both longer SFPs and more cumulative growing degree-days (Fig. 4b). The pattern for AGDD and vegetation productivity was similar (Fig. 4c), and neither result was statistically

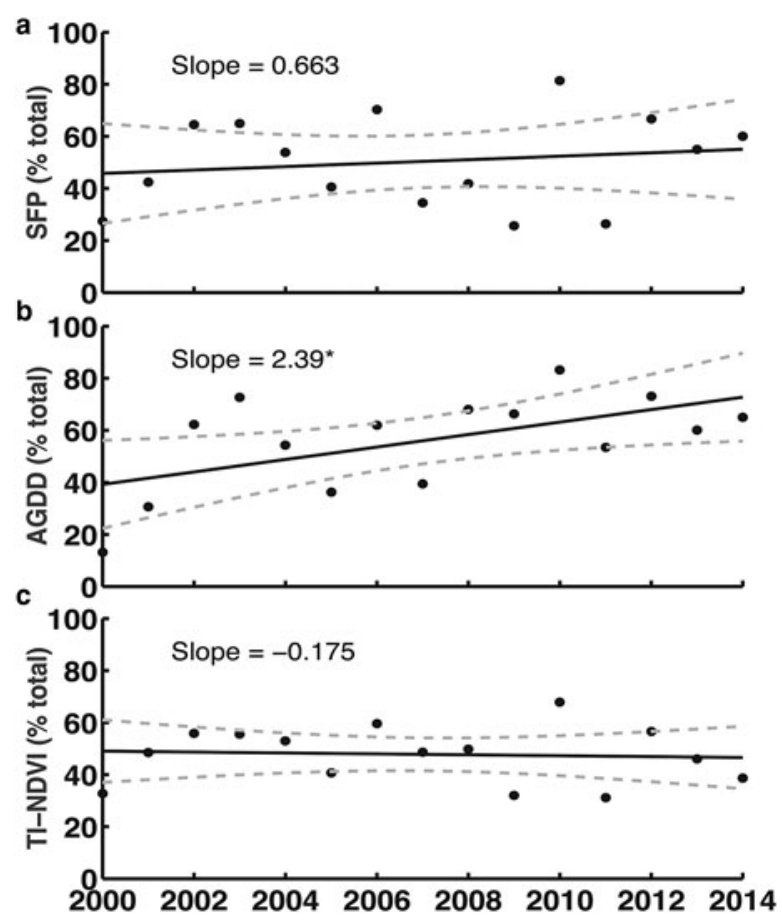

Fig. 3. (a) Changes in the percentage of vegetated pixels in Greenland that experienced longer than average duration of the snow-free period (SFP) from 2000 to 2014; (b) changes in the percentage of vegetated pixels that experienced more accumulated growing degree-days (AGDD) from 2000 to 2014; (c) changes in the percentage of vegetated pixels that exhibited above-average time-integrated NDVI (TI-NDVI) from 2000 to 2014. Solid lines represent the linear trends in the data; dashed lines represent the uncertainty (95\% confidence level) associated with the trends. Significance code: ${ }^{*} p \leq 0.05$. 

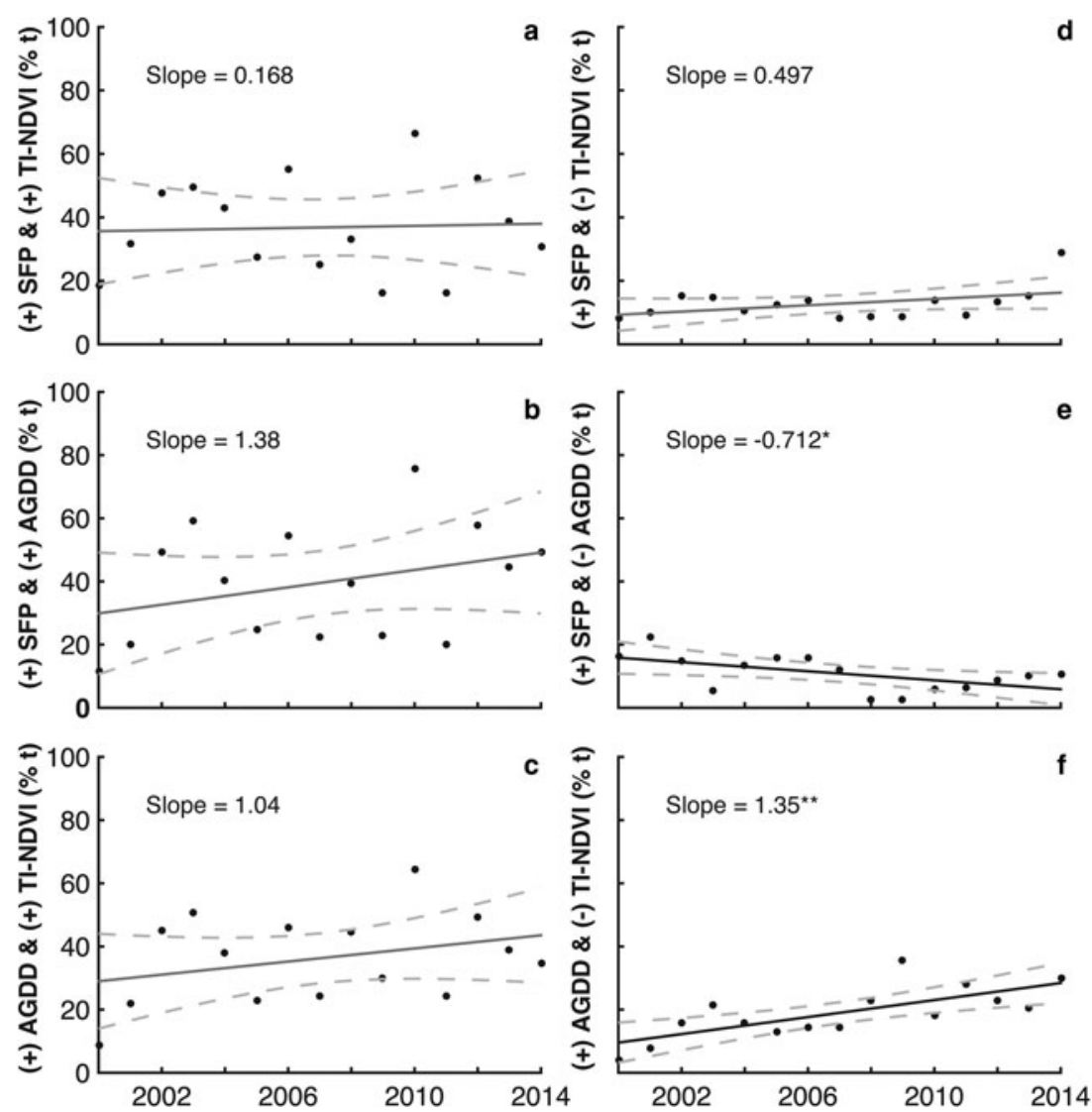

Fig. 4. (a) Changes in the percentage of vegetated pixels in Greenland that experienced both longer than average snow-free periods (SFP) and exhibited increased vegetation productivity (TI-NDVI); (b) changes in the percentage of pixels that experienced both above average SFP and increased numbers of accumulated growing degree-days (AGDD); (c) changes in the percentage of pixels that experienced both increased numbers of AGDD and exhibited increased TI-NDVI; (d) percentage of vegetation pixels that experienced above average duration of the SFP and also exhibited decreased TI-NDVI; (e) percentage of vegetation pixels experiencing both above average SFP and reduced numbers of AGDD; ( $f$ ) percentage of vegetation pixels that experienced increased AGDD and exhibited reduced TI-NDVI. Solid lines represent the linear trends in the data; dashed lines represent the uncertainty (95\% confidence level) associated with the trends. Significance codes: ${ }^{* *} p \leq 0.01 ;{ }^{*} p \leq 0.05$.

significant as there was considerable inter-annual variability evident (Figs $4 \mathrm{~b}$ and c). There was a statistically significant increase in the number of pixels that experienced both an increase in AGDD and reduced vegetation productivity (Fig. 4f).

\section{Basin-wide trends in snow seasonality, growing degree-days, and vegetation descriptors}

The full results for the basin-wide analysis are presented in the Supplementary Materials (Figs S5-S7), and only the joint descriptor results for basins 5 and 6 are presented in Figure 5. These were the only basins where statistically significant results were observed. Both basins experienced a reduction in the number of pixels that experienced longer than average SFPs and fewer numbers of growing degreedays (Figs $5 \mathrm{~b}$ and $\mathrm{c}$ ). Both basins had an increase in pixels with longer SFPs and reduced vegetation productivity during the study period (Figs $5 e$ and f).

\section{Maps results for the joint snow seasonality, growing degree-days, and vegetation descriptors}

Mapped results of the joint descriptor analysis for a cool (2000), average (2004) and a warm year (2010) are presented in Figure 6. In the cool and warm years, most of the pixels in
Western Greenland had descriptor values that were lower than average (cool; 2000) or higher than average (warm; 2010). In 2000, purple pixels featured prominently in all three maps in the cool year (2000) indicating ubiquitously low values for all of the descriptors. In contrast, in 2010, orange pixels dominated the map, which indicated a ubiquity of higher than average descriptor values. In 2010, the areas where the longer SFPs resulted in more growing degree-days and lower productivity (black areas for 2010, right most map Fig. 6) were also readily observed, particularly in Western Greenland.

\section{DISCUSSION}

This study had two major aims. Firstly, we wanted to determine whether or not longer SFPs were causing terrestrial Greenlandic vegetation to dry out. If there was evidence for the drying hypothesis, a subsequent aim of the study was to determine how extensive the drying phenomenon was. The results for the whole of Greenland indicated that $\sim 45 \%$ of the vegetated areas experienced increased SFPs that also coincided with an increase in AGDD (Fig. 4b). For many areas, this increase in growing degree-days also resulted in higher vegetation productivity (Fig. 4c). In others areas, more AGDD resulted in decreased productivity across the 

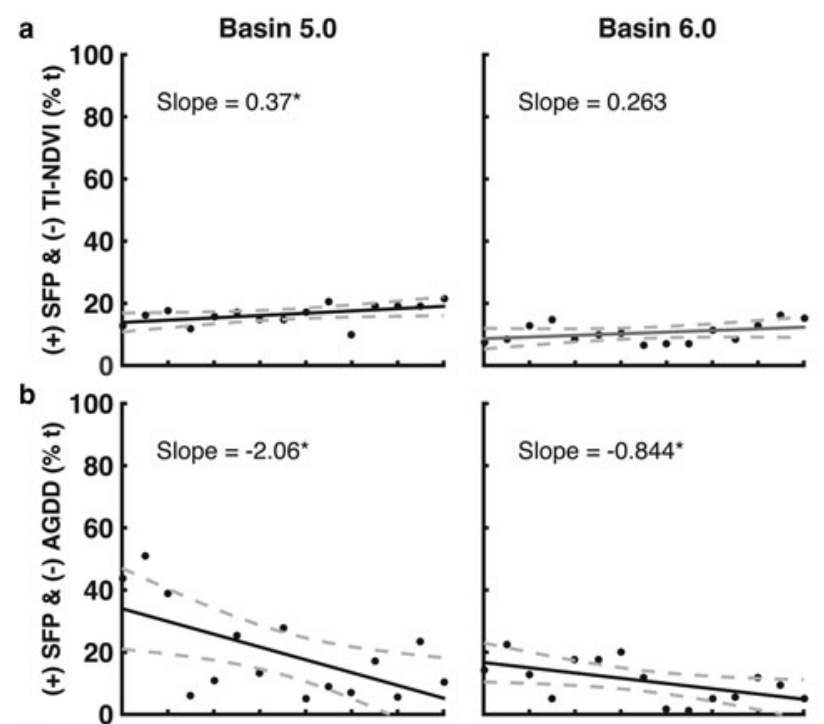

$$
\text { c }
$$

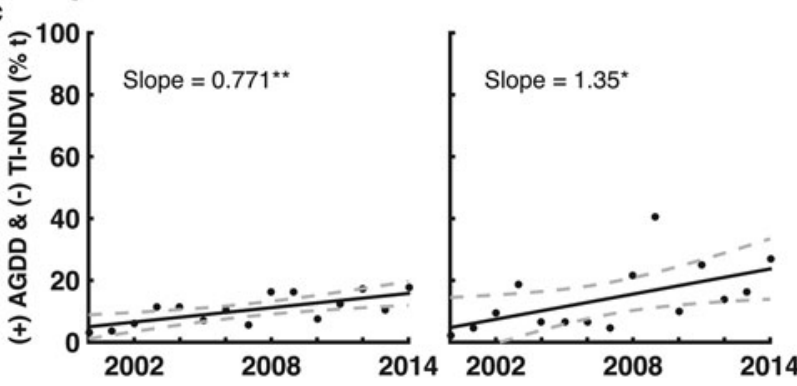

Fig. 5. (a) Changes in the percentage of vegetated pixels in basins 5.0 and 6.0 with longer than average SFP that also exhibited reduced TI-NDVI; (b) changes in the percentage of pixels that experienced both longer than average SFP and reduced numbers of AGDD; and (c) changes in the percentage of pixels that experienced increased numbers of AGDD and exhibited reduced TI-NDVI. Solid lines represent the linear trends in the data; dashed lines represent the uncertainty (95\% confidence level) associated with the trends. Significance codes: ${ }^{* *} p \leq 0.01 ;{ }^{*} p \leq 0.05$.

study period (Fig. 4f). This later result was statistically significant, and was consistent with the drying hypothesis.

Overall, $\sim 25 \%$ of the vegetated areas across Greenland experienced lower than average productivity. Although this phenomenon was not pervasive across the study period (as much as $60 \%$ of vegetated pixels experienced higher than average productivity in 2010; Fig. 4c), this result is important. In the southernmost basins (5-6), a statistically significant change in vegetation productivity was observed (Fig. 5c). In basins 5 and 6 , average productivity declined across the study period, even though they also experienced more growing degree-days than average. This phenomenon is consistent with the drying hypothesis.

The results presented here suggested that changes associated with increased energy inputs are potentially more complex than originally predicted by the Budyko (1974) framework. The combination of longer SFPs and more AGDD should have resulted in higher vegetation productivity, according to the framework. The framework does not account for the fact that some pixel's productivity decreased when they were exposed to increased energy inputs and experienced similar climatic conditions as the pixels where productivity increased. Local hydrologic changes represent one possible explanation, as vegetation still requires access to water in order to maintain or increase productivity. Our results suggest that water stress may play an increasingly important role in maintaining vegetation productivity in some areas of Greenland (e.g. basins 5-6; Fig. 5c). For these areas, micro-meteorological and local environmental conditions are likely more influential drivers of vegetation phenology than mesoscale and synoptic scale warming associated with Arctic amplification.

What remains unclear is what ultimately contributed to the reduction in vegetation productivity that was observed in these basins. Interestingly, in basins 5 and 6, many areas where decreased productivity was observed were situated closer to the edge of the ice sheet (Fig. 6c). Whether or not this corresponded with changes in precipitation during study period is unclear; exploratory modeling of the data (not presented) did not yield any conclusive results in this regard. It is possible that the reductions in vegetation productivity were associated with localized phenomena. Foehn (or, adiabatically warmed katabatic) winds are one possible explanation. In Greenland, it has long been observed that localized warming associated with foehn winds can dramatically reduce snow cover over relative short periods (Thing, 1984). When precipitation falls, the temperature of air parcels that previously contained moisture increases. As these parcels subsequently descend to lower elevations, they add additional heat to the land surface. This can melt snow cover (Thing, 1984), which is an important driver of vegetation phenology in the Arctic. Foehn winds could account for the localized reductions in vegetation productivity that we observed in this study, particularly in areas close to the ice sheet. Investigating this possibility represents a possible avenue for further research.

While our results appeared to support the drying hypothesis, there were some limitations with this study. One limitation related to the use of the fractional snow cover data. The MOD10A1 FSC product tends to underestimate the amount of snow cover within a pixel, particularly in the transitions into and out of the snow-covered period (Rittger and others, 2013). This could have biased our estimates for the duration of the SFP. However, the sensitivity analysis (Supplementary Results) indicated that using different snow cover thresholds did not substantially affect the snow seasonality descriptor dates. As a result, it is unlikely that potential bias in MOD10A1 FSC data would significantly impact the results presented here.

The use of NDVI time series to assess vegetation phenology represents another potential limitation associated with this study. When present, NDVI signals are attenuated by both snow cover and water. As previously noted, our algorithm tried to minimize these effects but it is possible that some sub-pixel snow cover or water was present within some vegetated pixels during the study period. Medium- to long-term changes in small persistent water bodies would be particularly problematic for this analysis. They would depress the NDVI signal through time, thereby reducing the yearly TI-NDVI signal. It would be difficult to differentiate the effects of sub-pixel water accumulation from that of drying vegetation using NDVI. This represented another limitation of our study.

We do not think sub-pixel water accumulation significantly impacted our results. The spatial patterns we observed in our results were similar to those presented by Watts and others (2014) in their study of open water in the Arctic. A visual inspection of our results with the trend analysis presented by Watts and others (2014) revealed that the areas 


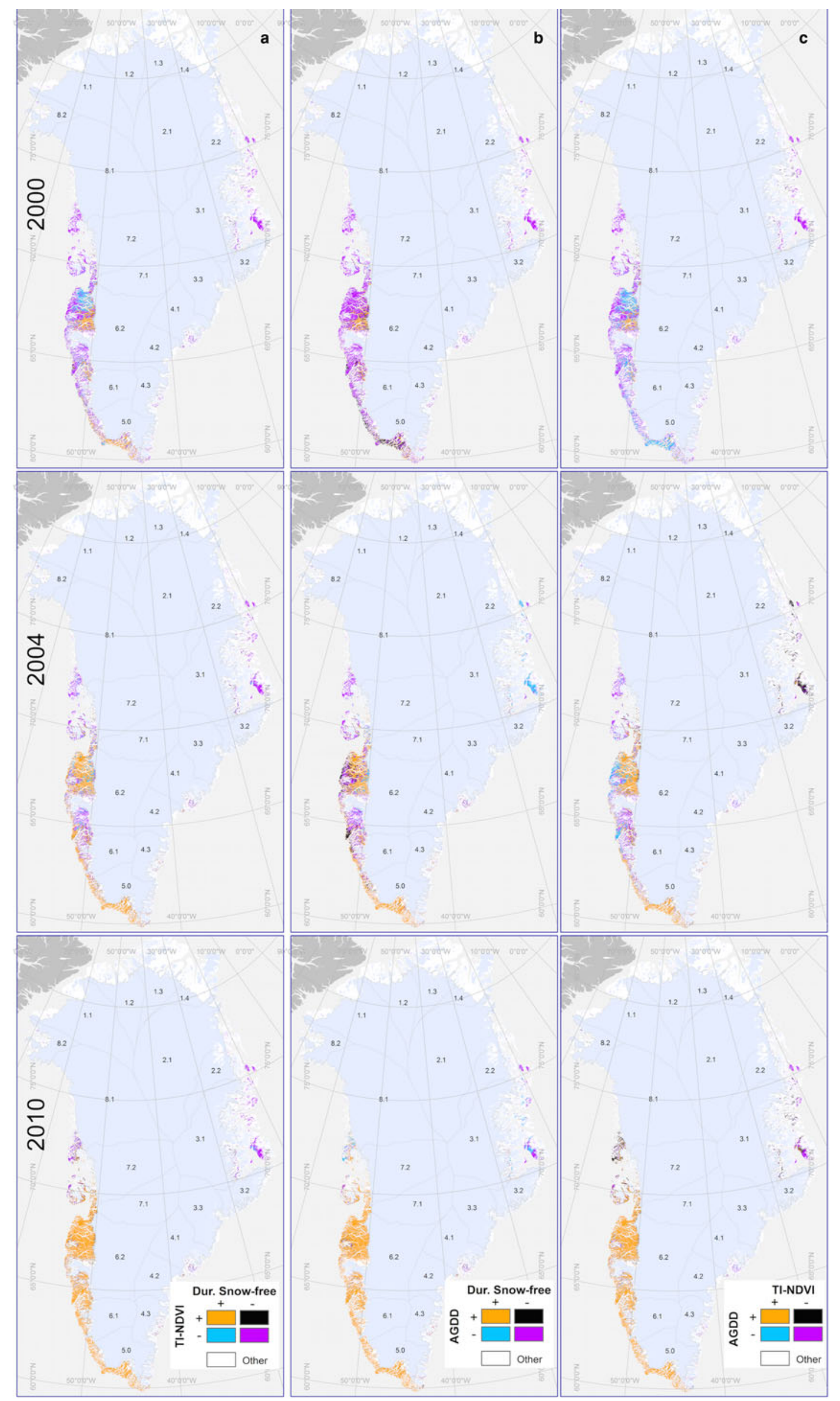

Fig. 6. Mapped results for the joint descriptor analysis representing combinations of higher (+)/lower (-) than average: (a) time-integrated NDVI (TI-NDVI) and duration of the snow-free period (SFP); (b) accumulated growing degree-days (AGDD) and duration of the snow-free period (SFP); and (c) accumulated growing degree-days (AGDD) and time-integrated NDVI (TI-NDVI). Patterns were representative of a cool (2000), an average (2004) and a warm year (2010) within the time series. A larger version of this map is included in the Supplementary Materials. 
where we observed decreasing productivity were similar to the areas where those authors reported that the fraction of open water decreased throughout their study. Differences in spatial resolutions and study periods precluded direct quantitative comparisons of the results presented here and those reported by Watts and others (2014). However, the visual similarities in both results suggest that water accumulation did not unduly influence our analysis, though it does warrant further investigation. A quantitative comparison could serve as an independent validation of our findings and this represents another potential avenue for future research.

\section{CONCLUSION}

This study used three image time series obtained by MODIS to determine whether or not longer SFPs might be causing terrestrial vegetation to dry out in Greenland. In some vegetated areas, the remotely sensed observations were consistent with the drying hypothesis. Drying affected $\sim 25 \%$ of Greenland's vegetated pixels, and was more pronounced in basins located in Southwestern Greenland. Our results also suggest that the localized impacts associated with drying were more nuanced than could be predicted by the Budyko (1974) eco-hydrological framework.

\section{SUPPLEMENTARY MATERIAL}

The supplementary material for this article can be found at https://doi.org/10.1017/aog.2018.24

\section{ACKNOWLEDGEMENTS}

J.A.T. was supported by the Postdoctoral Visiting Fellowship Program at the Cooperative Institute for Research in Environmental Sciences at the University of Colorado. J.A. T. wishes to thank Mahsa Mousavi and Alan Pope for discussions and helpful comments, and Karl Rittger for helpful MATLAB suggestions throughout the project. We thank the reviewers for their thoughtful and insightful comments, which greatly helped improve the manuscript. We are not aware of any conflicts of interest regarding this work. Publication of this article was funded by the University of Colorado Boulder Libraries Open Access Fund.

\section{REFERENCES}

Andersen T and Poppel B (2002) Living conditions in the Arctic. Soc. Indic. Res., 58(1-3), 191-216 (doi: 10.1023/A:1015787901370)

Beck PSA and Goetz SJ (2011) Satellite observations of high northern latitude vegetation productivity changes between 1982 and 2008: ecological variability and regional differences. Environ. Res. Lett., 6(4), 10pp (doi: 10.1088/1748-9326/6/4/045501)

Bhatt US and 10 others (2010) Circumpolar Arctic tundra vegetation change is linked to Sea Ice decline. Earth Interact., 14, (doi: 10.1175/2010ei315.1)

Bhatt US and 8 others (2013) Recent declines in warming and vegetation greening trends over Pan-Arctic Tundra. Remote Sens., 5 (9), 4229-4254 (doi: 10.3390/rs5094229)

Budyko MI (1974). Climate and life. Academic Press, New York

Callaghan TV, Christensen TR and Jantze EJ (2011) Plant and vegetation dynamics on Disko Island, West Greenland: snapshots separated by over 40 years. Ambio, 40(6), 624-637 (doi: 10.1007/s13280-011-0169-x)

Carroll ML, Townshend JR, DiMiceli CM, Noojipady P and Sohlberg RA (2009) A new global raster water mask at $250 \mathrm{~m}$ resolution. Int. J. Digit. Earth, 2(4), 291-308 (doi: 10.1080/ 17538940902951401)

Carroll ML, Wooten M, DiMiceli C, Sohlberg R and Kelly M (2016) Quantifying surface water dynamics at 30 meter spatial resolution in the North American high northern latitudes 1991-2011. Remote Sens., 8(8), 14pp (doi: 10.3390/rs8080622)

Coll C and 6 others (2005) Ground measurements for the validation of land surface temperatures derived from AATSR and MODIS data. Remote Sens. Environ., 97(3), 288-300 (doi: 10.1016/j. rse.2005.05.007)

Daniëls FJA and de Molenaar JG (2011) Flora and vegetation of Tasiilaq, formerly Angmagssalik, Southeast Greenland: a comparison of data between around 1900 and 2007. Ambio, 40(6), 650-659 (doi: 10.1007/s13280-011-0171-3)

Daniëls FJA, de Molenaar JG, Chytry M and Tichy L (2011) Vegetation change in Southeast Greenland? Tasiilaq revisited after 40 years. Appl. Veg. Sci., 14(2), 230-241 (doi: 10.1111/ j.1654-109X.2010.01107.x)

Derksen C and Brown R (2012) Spring snow cover extent reductions in the 2008-2012 period exceeding climate model projections. Geophys. Res. Lett., 39(L19504), 6pp (doi: 10.1029/2012 GL053387)

Déry SJ and Brown RD (2007) Recent Northern Hemisphere snow cover extent trends and implications for the snow-albedo feedback. Geophys. Res. Lett., 34, L22504 (doi: 10.1029/2007GL031474)

Dozier J (1989) Spectral signature of alpine snow cover from the Landsat Thematic Mapper. Remote Sens. Environ., 28, 9-22 (doi: 10.1016/0034-4257(89)90101-6)

Ellebjerg SM, Tamstorf MP, Illeris L, Michelsen A and Hansen BU (2008) Inter-annual variability and controls of plant phenology and productivity at Zackenberg. Adv. Ecol. Res., 40: 249-273 (doi: 10.1016/S0065-2504(07)00011-6)

Enderlin EM and 5 others (2014) An improved mass budget for the Greenland Ice Sheet. Geophys. Res. Lett., 41(3), 866-872 (doi: 10.1002/2013GL059010)

Francis JA and Hunter E (2006) New insight into the disappearing Arctic sea ice. EOS (Washington. DC), 87(46), 509-511 (doi: 10.1029/2006EO460001)

Graversen RG, Mauritsen T, Tjernstrom M, Kallen E and Svensson G (2008) Vertical structure of recent Arctic warming. Nature, 451 (7174), 53-U54 (doi: 10.1038/nature06502)

Hall DK and Riggs GA (2007) Accuracy assessment of the MODIS snow products. Hydrol. Processes, 21(12), 1534-1547 (doi: 10.1002/hyp.6715)

Hall DK, Riggs GA, Salomonson VV, DiGirolamo NE and Bayr KJ (2002) MODIS snow-cover products. Remote Sens. Environ., 83(1-2), 181-194 (doi: 10.1016/S0034-4257(02)00095-0)

Hall DK and 5 others (2013) Variability in the surface temperature and melt extent of the Greenland Ice Sheet from MODIS. Geophys. Res. Lett., 40(10), 2114-2120 (doi: 10.1002/grl.50240)

Haran T, Bohlander J, Scambos T, Painter TH and Fahnestock M (2013) MEaSUREs MODIS Mosaic of Greenland 2005 (MOG2005) Image Map, version 1. NSIDC, Boulder, Colorado, USA

Higuera PE and 5 others (2008) Frequent fires in ancient shrub tundra: implications of paleorecords for Arctic environmental change. PLoS ONE, 3(3), e0001744 (doi: 10.1371/journal. pone.0001744)

Howat IM, Negrete A and Smith BE (2014) The Greenland Ice Mapping Project (GIMP) land classification and surface elevation data sets. Cryosphere, 8(4), 1509-1518 (doi: 10.5194/tc-8-15092014)

Huete AR and 5 others (2002) Overview of the radiometric and biophysical performance of the MODIS vegetation indices. Remote Sens. Environ., 83(1-2), 195-213 (doi: 10.1016/S0034-4257(02)00096-2)

Jia GJ, Epstein HE and Walker DA (2009) Vegetation greening in the Canadian Arctic related to decadal warming. J. Environ. Monitor., 11(12), 2231-2238 (doi: 10.1039/b911677j)

Justice CO, Holben BN and Gwynne MD (1986) Monitoring eastAfrican vegetation using AVHRR data. Int. J. Remote Sens., 7 (11), 1453-1474 (doi: 10.1080/01431168608948948) 
Kahn B (2017). Wildfire burns across (formerly) Icy Greenland: grasses and low vegetation on the defrosting, drying tundra are igniting. Scientific American, https:/www.scientificamerican.com/article/ wildfire-burns-across-formerly-icy-greenland/ (29 May 2018)

Kirschbaum M and Farquhar G (1984) Temperature dependence of whole-leaf photosynthesis in eucalyptus pauciflora Sieb. Ex Spreng. Aust. J. Plant Physiol., 1984(11), 519-538 (doi: 10.1071/ PP9840519)

Körner C (1998) A re-assessment of high elevation treeline positions and their explanation. Oecologia, 115(4), 445-459 (doi: $10.1007 /$ s004420050540)

Markus T, Stroeve JC and Miller J (2009) Recent changes in Arctic sea ice melt onset, freezeup, and melt season length. J. Geophys. Res. Oceans, 114, 14pp (doi: 10.1029/2009jc005436)

MathWorks (2016) MATLAB and the statistics toolbox release 2016a. The MathWorks, Inc., Natick, MA, USA

McCabe GJ and Wolock DM (2010) Long-term variability in Northern Hemisphere snow cover and associations with warmer winters. Clim. Change, 99(1-2), 141-153 (doi: 10.1007/s10584-009-9675-2)

Myneni RB, Keeling CD, Tucker CJ, Asrar G and Nemani RR (1997) Increased plant growth in the northern high latitudes from 1981 to 1991. Nature, 386(6626), 698-702 (doi: 10.1038/386698a0)

Myers-Smith IH and 31 others (2011) Shrub expansion in tundra ecosystems: dynamics, impacts and research priorities. Environ. Res. Lett., 6(4) (doi: 10.1088/1748-9326/6/4/045509)

Nobel PS (2009) Physicochemical and environmental plant physiology, 4th edn. Elsevier, Oxford

Pomeroy JW and Brun E (2001) Physical properties of snow. In Jones HG, Pomeroy JW, Walker DA and Hoham RW eds. Snow ecology: an interdisciplinary examination of snow-covered ecosystems. Cambridge University Press, Cambridge, 45-126

Pomeroy JW, Holler P, Marsh P, Walker DA and Williams M (2001) Snow vegetation interactions: issues for a new initiative. In SoilVegetation-Atmosphere Transfer Schemes and Large-Scale Hydrological Models, Proceedings of a Symposium held During the Sixth IAHS Scientific Assembly, Maastricht, The Netherlands, 18-27 July 2001, 299-305

Reed BC and 5 others (1994) Measuring phenological variability from satellite imagery. J. Veg. Sci., 5(5), 703-714 (doi: 10.2307/3235884)

Reed BC, Budde M, Spencer P and Miller AE (2009) Integration of MODIS-derived metrics to assess interannual variability in Snowpack, Lake Ice, and NDVI in southwest Alaska. Remote Sens. Environ., 113(7), 1443-1452 (doi: 10.1016/j.rse.2008.07.020)

Reed BC, White MA and Brown JF (2003) Remote sensing phenology. In Schwartz MD ed. Phenology: An Integrative Environmental Science. Kluwer Academic Publisher, Dordrecht, The Netherlands 365-381

Riggs GA, Hall DK and Salomonson VV (2006) MODIS snow products user guide to collection 5. NASA Goddard Space Flight Center, Greenbelt, Maryland

Rittger K, Painter TH and Dozier J (2013) Assessment of methods for mapping snow cover from MODIS. Adv. Water Resour., 51: 367-380 (doi: 10.1016/j.advwatres.2012.03.002)

Salomonson VV and Appel I (2004) Estimating fractional snow cover from MODIS using the normalized difference snow index. Remote Sens. Environ., 89(3), 351-360 (doi: 10.1016/j. rse.2003.10.016)

Screen JA and Simmonds I (2010) The central role of diminishing sea ice in recent Arctic temperature amplification. Nature, 464 (7293), 1334-1337 (doi: 10.1038/nature09051)

Sellers PJ (1985) Canopy reflectance, photosynthesis and transpiration. Int. J. Remote Sens., 6(8), 1335-1372 (doi: 10.1080/ 01431168508948283)
Serreze MC and 9 others (2000) Observational evidence of recent change in the northern high-latitude environment. Clim. Change, 46(1-2), 159-207 (doi: 10.1023/a:1005504031923)

Shepherd A and 47 others (2012) A reconciled estimate of ice-sheet mass balance. Science, 338(6111), 1183-1189 (doi: 10.1126/ science.1228102)

Smith LC, Sheng Y, MacDonald GM and Hinzman LD (2005) Disappearing Arctic lakes. Science, 308(5727), 1429-1429 (doi: 10.1126/science.1108142)

Solano R, Didan K, Jacobson A and Huete A (2010) MODIS vegetation indices (MOD13) C5 user's guide. The University of Arizona, Tucson, Arizona

Sturm M, Douglas T, Racine C and Liston GE (2005) Changing snow and shrub conditions affect albedo with global implications. J. Geophys. Res. Biogeo., 110(G1), (doi: 10.1029/2005jg000013)

Sturm $M$ and 5 others (2001) Snow-shrub interactions in Arctic tundra: a hypothesis with climatic implications. J. Clim., 14(3), 336-344 (doi: 10.1175/1520-0442(2001)014<0336:ssiiat >2.0.co;2)

Thing H (1984) Feeding ecology of the West Greenland caribou (Rangifer tarandus groenlandicus) in the Sisimiut/Kangerlussuaq region. Danish Rev. Game Biol., 12(3), 53p

Tucker CJ (1979) Red and photographic infrared linear combinations for monitoring vegetation. Remote Sens. Environ., 8(2), 127-150 (doi: 10.1016/0034-4257(79)90013-0)

Voiland A (2017) Fire and ice in Greenland: natural hazards. Earth Observatory, NASA, Greenbelt, Maryland. https://earthobservatory.nasa.gov/Natural Hazards/view.php?id=90709\&src=nha, $(29$ May 2018)

Walker DA, Billings WD and de Mollenaar JG (2001) Snow-vegetation interactions in tundra environments. In Jones HG, Pomeroy JW, Walker DA and Hoham RW eds. Snow ecology: an interdisciplinary examination of snow-covered ecosystems, Cambridge University Press, Cambridge, 266-324

Wan ZM (2007) Collection-5 MODIS land surface temperature products users' guide. ICESS, University of California, Santa Barbara

Wan ZM (2008) New refinements and validation of the MODIS land-surface temperature/emissivity products. Remote Sens. Environ., 112(1), 59-74 (doi: 10.1016/j.rse.2006.06.026)

Wan ZM and Dozier J (1996) A generalized split-window algorithm for retrieving land-surface temperature from space. IEEE T. Geosci. Remote, 34(4), 892-905 (doi: 10.1109/ 36.508406)

Wan ZM, Zhang YL, Zhang QC and Li ZL (2002) Validation of the land-surface temperature products retrieved from Terra Moderate Resolution Imaging Spectroradiometer data. Remote Sens. Environ., 83(1-2), 163-180 (doi: 10.1016/s0034-4257(02) 00093-7)

Watts JD, Kimball JS, Bartsch A and McDonald KC (2014) Surface water inundation in the boreal-Arctic: potential impacts on regional methane emissions. Environ. Res. Lett., 9(7), 14pp (doi: 10.1088/1748-9326/9/7/075001)

White MA and 20 others (2009) Intercomparison, interpretation, and assessment of spring phenology in North America estimated from remote sensing for 1982-2006. Glob. Change Biol., 15(10), 2335-2359 (doi: 10.1111/j.1365-2486.2009. 01910.x)

Wielgolaski FE and Inouye DW (2013) Phenology at High Latitudes. In Schwartz $\mathrm{M}$ ed. Phenology: An Integrative Environmental Science. Springer, Dordrecht 225-247

Zwally HJ, Giovinetto MB, Beckley MA and Saba JL (2012) Antarctic and Greenland drainage systems. GSFC Cryospheric Sciences Laboratory, NASA, Greenbelt, Maryland 